\title{
Use of Imaging Spectroscopy for Mapping and Quantifying the Weathering Degree of Tropical Soils in Central Brazil
}

\author{
Gustavo M. M. Baptista, ${ }^{1}$ Rodrigo S. Corrêa, ${ }^{2,3}$ Perseu F. dos Santos, ${ }^{3,4}$ \\ José S. Madeira Netto, ${ }^{5}$ and Paulo R. Meneses ${ }^{1}$ \\ ${ }^{1}$ Geosciences Institute, University of Brasilia, 70910-900 Brasilia, DF, Brazil \\ ${ }^{2}$ Department of Ecology, University of Brasilia, 70910-900 Brasilia, DF, Brazil \\ ${ }^{3}$ Environmental Planning and Management Program, Catholic University of Brasilia, 72030-170 Brasilia, DF, Brazil \\ ${ }^{4}$ College of Arts and Science, New Mexico State University, Las Cruses, NM 88003, USA \\ ${ }^{5}$ Brazilian Agricultural Research Corporation, Embrapa 70770-901 Brasilia, DF, Brazil
}

Correspondence should be addressed to Gustavo M. M. Baptista, gmbaptista@unb.br

Received 13 November 2010; Revised 15 February 2011; Accepted 3 March 2011

Academic Editor: Michel C. Nolin

Copyright (C) 2011 Gustavo M. M. Baptista et al. This is an open access article distributed under the Creative Commons Attribution License, which permits unrestricted use, distribution, and reproduction in any medium, provided the original work is properly cited.

\begin{abstract}
The purpose of this study was to test the feasibility of applying AVIRIS sensor (Airborne Visible/InfraRed Imaging Spectrometer) for mapping and quantifying mineralogical components of three Brazilian soils, a reddish Oxisol in São João D’Aliança area (SJA) and a dark reddish brown Oxisol and Ultisol in Niquelândia (NIQ) counties, Goiás State. The study applied the spectral index RCGb [kaolinite/(kaolinite + gibbsite) ratio] and was based on spectral absorption features of these two minerals. The RCGb index was developed for the evaluation of weathering degrees of various Brazilian soils and was validated by the analysis of soil samples spectra imaged by AVIRIS and checked against laboratory mineralogical quantification (TGA:Thermal Gravimetric Analysis). Results showed to be possible mapping and quantifying the weathering degree of the studied soils and that the two selected areas presented different weathering degrees of their soils even for a same soil type.
\end{abstract}

\section{Introduction}

Soil is a product of forming factors such as parent material, climate, time, organisms, and topography. The great variability in soils results from interactions of these factors and their influence on the formation of different soil profiles. Mineral types and their proportions in soils are also dependable on soil-forming factors and have strong influence on agriculture, forestry, soil engineering, among others [1].

Tropical soil scontain mineralogical variations that cannot be perceived in field works. The determination of soil mineral composition depends on laboratory analysis of soil samples collected in field, and an extrapolation of the representativeness of the results to a broader area depends on landscape morphological characteristics and accuracy of the field work [2]. For cartographic purposes, the spatial distribution of values from point-sampled minerals is done by using morphological criteria in correlation with topography, parent material, and other parameters.
Reliable criteria to discriminate soils with varied amounts of kaolinite and gibbsite do not exist, and the quantification of these two minerals in soils demands systematic samplings with high-density points. Because this procedure greatly increases costs of soil surveys, new techniques and resources that can ease pedological surveys are strongly desirable. Recent advances in remote sensing with the image spectroscopy appear to be a promising alternative in soil science. However, most of the optical remote sensing means cannot detect the entire soil body ("pedon") that extends from the surface to the parent material, and the thin, upper soil layer that is eventually sensed by optical sensors may be affected by many factors such as dust, rust, plowing, particle size distribution, vegetation coverage, litter, and physical and biogenic crusts. Thus, optical remote sensing of soils from far distances is a challenge [1].

Laboratory spectral analysis and multispectral data analysis have been utilized to detect the occurrence of some soil main components [2-18]. It is well known that a wide range 
of soil constituents such as the total iron, water content, mechanical compositions, carbonate, and organic carbon can be derived through reflectance spectroscopy under laboratory conditions [1]. Many studies have pointed out the possibility of using hyperspectral images to display the occurrence and variation in concentrations of minerals in some pedological sequences in tropical environments, expanding the contribution of these new remote sensing products to soil research studies $[1,19-32]$. In this sense, one of the most important factors for mapping pedological environments is to spatialized and map different degrees of soil weathering. A spatial differentiation in mineralogy is important for elucidating soil genesis processes, determining the most appropriate management systems, and classifying soils.

Soil formation in the tropics (i.e. Oxisols) is characterized by the remotion of $\mathrm{SiO}_{2}$, followed by the increase in $\mathrm{Al}_{2} \mathrm{O}_{3}$ concentration. The weathering degree of a soil is usually depicted by the $\mathrm{Ki}$ index, which is the molecular ratio of $\mathrm{SiO}_{2}$ to $\mathrm{Al}_{2} \mathrm{O}_{3}$. In the $\mathrm{RCGb}$ index kaolinite/ (kaolinite + gibbsite), kaolinite $\left[\mathrm{Al}_{2} \mathrm{Si}_{2} \mathrm{O}_{5}(\mathrm{OH})_{4}\right]$ represents the $\mathrm{SiO}_{2}$ leftover and gibbsite $\left[\mathrm{Al}(\mathrm{OH})_{3}\right]$ represents the $\mathrm{Al}_{2} \mathrm{O}_{3}$ concentration in soils [27].

Therefore, the purpose of this study was to evaluate the feasibility of applying a hyperspectral sensor (AVIRIS) for mapping and quantifying the weathering degree of some Brazilian soils.

\section{Material and Methods}

2.1. AVIRIS Sensor. AVIRIS (Airborne Visible/InfraRed Imaging Spectrometer) is one of the hyperspectral sensors that currently operate. It is an aerotransported system consisting of four spectrometers that continuously image at 0.4 to $2.5 \mu \mathrm{m}$ range of the optical reflected spectrum, on 224 bands, with approximate width of $10 \mathrm{~nm}$, owned by the Jet Propulsion Laboratory (JPL/NASA). It was the first hyperspectral sensor to image Brazilian soils, and it has been used for rock, soil, vegetation, water, and snow mapping in many countries.

2.2. RCGb Spectral Index. Many hyperspectral sensors can detect kaolinite and gibbsite in soils but the presence of $\mathrm{Al}_{2} \mathrm{O}_{3}$ in both of the minerals spoils the use of $\mathrm{Ki}$ index (molecular ratio of $\left[\mathrm{SiO}_{2}\right] /\left[\mathrm{Al}_{2} \mathrm{O}_{3}\right]$ ) in remote sensing. Therefore, indexes derived from $\mathrm{Ki}$ have been proposed to make possible the use of remote sensing for soil mapping [2]. The spectral index RCGb(kaolinite/kaolinite + gibbsite) used in this work was proposed by Baptista [33, Equation 1].It is based on the spectral features of kaolinite and gibbsite and the values obtained with RCGb index have been showed to be proportional to Ki values. One can use the RCGb with either radiance $(\mathrm{R})$ or reflectance $(\mathrm{R})$ spectra because the spectral features of kaolinite and gibbsite are present in both spectra (1).

$$
\mathrm{RCGb}=\frac{\left(\left(R_{2,127}+R_{2,226}\right) / 2-\left(R_{2,176}+R_{2,196}\right) / 2\right)}{\left(\left(R_{2,127}+R_{2,226}\right) / 2-\left(R_{2,176}+R_{2,196}\right) / 2\right)+\left(\left(R_{2,226}+R_{2,286}\right) / 2-R_{2,266}\right)},
$$

where $R$ is the radiance $\left(\mathrm{W} \cdot \mathrm{m}^{-2} \cdot \mathrm{sr}^{-1}\right)$ or reflectance value (\%) in various wavelengths adapted to the AVIRIS' bands.

Validation of the RCGb spectral index adopted the same reflectance spectra analyzed by Madeira Netto [2] for 56 soil samples that correspond to the surface and deeper layers of 27 soil profiles [27]. Out of the 56 spectra, four samples with opaque minerals were removed, although these minerals have an influence on the determination of the RCGb spectral index. However, they are not a factor that impedes applicability, although they do slightly reduce the RCGb index efficiency [33]. The correlation factor between the RCGb index and Ki values for the 52 samples was $r=0.93, P<.01)$.

2.3. Study Areas. The study imaged areas considered a red-dish Oxisol transect in São João D’Aliança (SJA), a dark reddish brown Oxisol, and an Ultisol in Niquelândia (NIQ) counties, Goiás State, central part of Brazil (Figure 1). Most of the differences measured between hyperspectral images and their targets are rather explained by spectral calibration uncertainties, like relative radiometric calibration and errors in atmospheric correction, particularly when regarding water vapor, which has significant absorption features in the spectral domains $(2143-2269 \mathrm{~nm})$ used for clay content estimations [34]. In this regard, Baptista [33] found no significant differences between radiance images and reflectance data corrected by the Green's method [35] or by Atmospheric Removal Program (ATREM) [36, 37] for Brazilian soil minerals. Therefore, the radiance raw data were neither corrected for atmospheric effects nor reduced to scaled surface reflectance of in this study.

The RCGb spectral index was applied to the concatenated AVIRIS data (Figure 2), as they were obtained on the same day with less than $1 / 2$ hour between acquisitions-the flight over São João D’Aliança(SJA) and Niquelândia (NIQ) counties, Goiás State, Brazil. As neither image presented clouds, and the official website of the SCAR-B mission (http://asd-www.larc.nasa.gov/scar/scarb.html in June 8th 2000) considered the atmospheric conditions of the entire flight on that day to be "slight mist, no clouds, small fires, one large fire," it was assumed that the atmospheric conditions did not significantly vary from one image to the other. Working scale was based on AVIRIS spatial dimension of $20 \mathrm{~m}$ and which correspond to 1:50,000.

A topological sequence was chosen in SJA (13 imaged plots, 1-13) and another in NIQ area (17 imaged plots, 1-17; Figure 2). The distance between surveying plots was of $100 \mathrm{~m}$ (Figure 2), covering $1.2 \mathrm{~km}$ in SJA and $1.6 \mathrm{~km}$ in NIQ. Soil samples were collected between $0-20 \mathrm{~cm}$ soil depth from the same sequence with an auger for mineralogical analyses in laboratory (Thermal Gravimetric Analysis, TGA). 


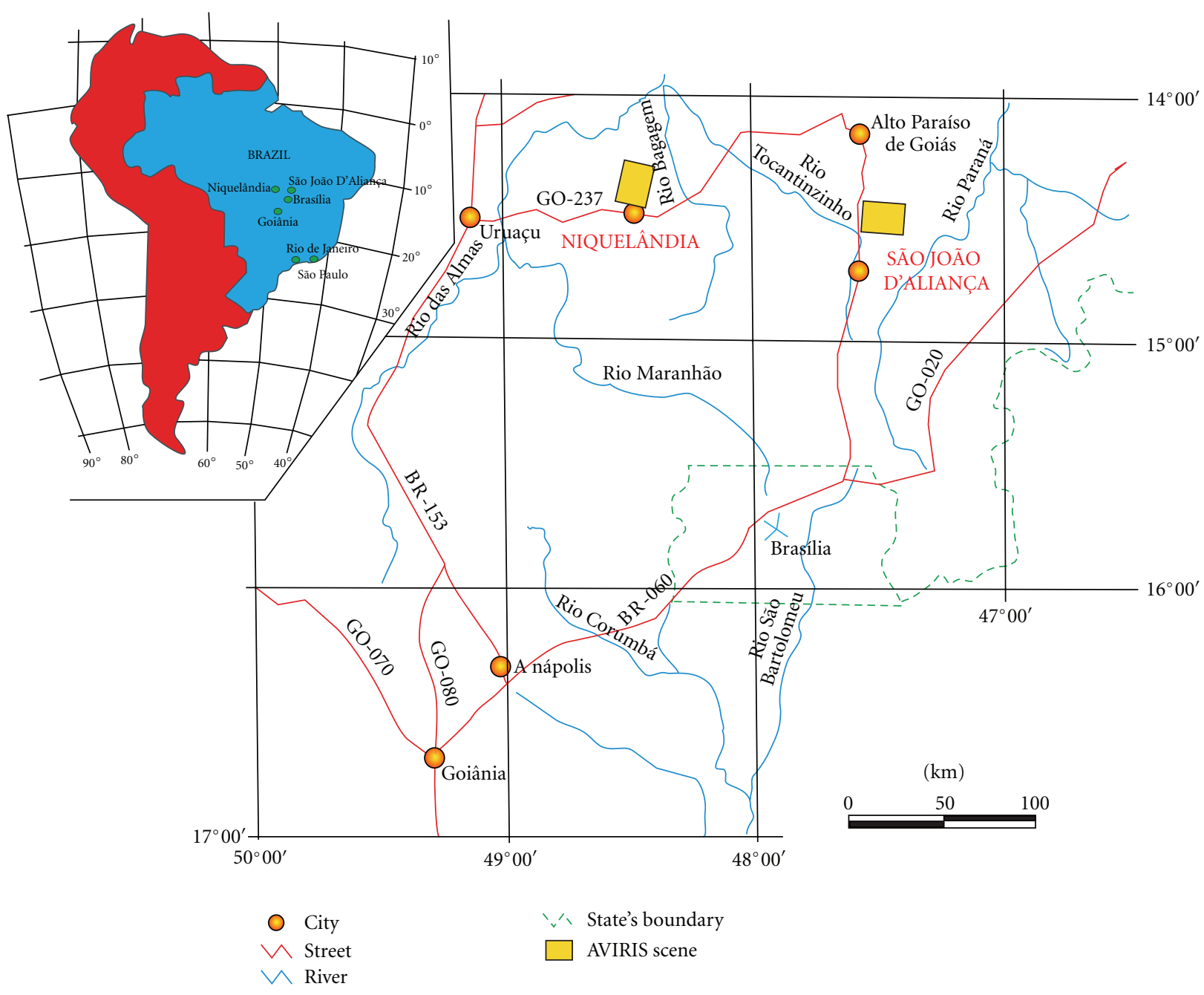

Figure 1: Study areas in central Brazil.

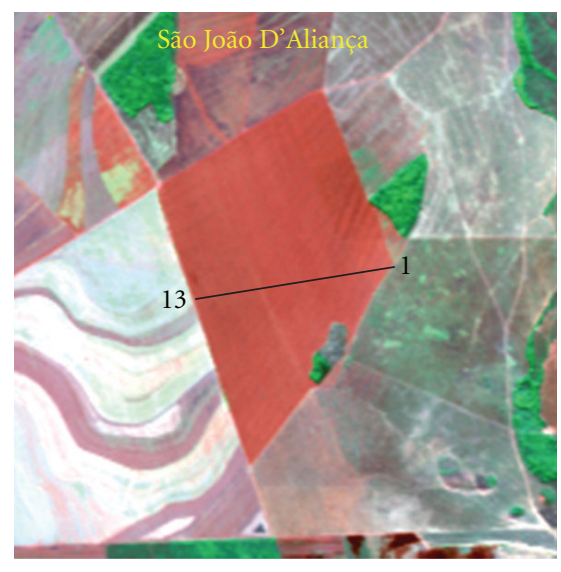

(a)

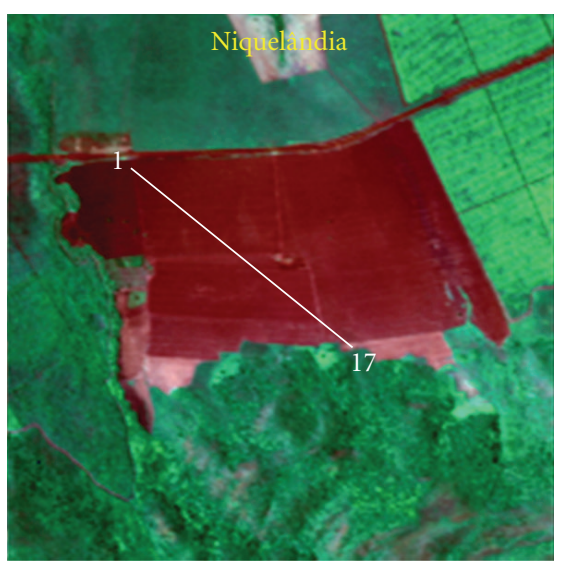

(b)

FIGURE 2: AVIRIS images of the areas, showing differences in soil grey scale due to either the absence (SJA)or the presence (NIQ) of opaque minerals $(1: 50,000)$. 


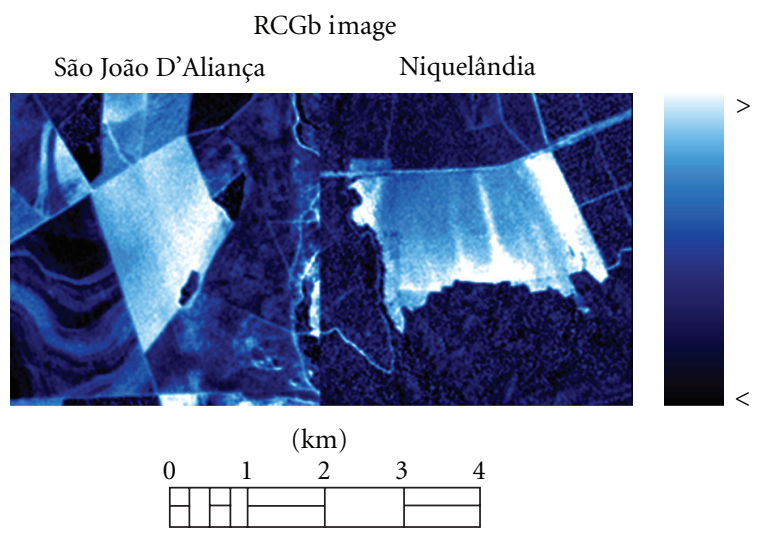

FIGURE 3: Spatial distribution of RCGb values in SJA and NIQ.

Comparisons between AVIRIS and TGA data were done by statistical methods, and AVIRIS data were then scaled for correction purposes for quantifying the weathering degree of the soils.

Response units of the two procedures (AVIRIS and TGA) to determine the RCGb refer to index, and the use of parametric tests is not appropriated. Thus, the MannWhitney test was used to compare the two sets of data [38].

\section{Results and Discussion}

The greater the value of RCGb, the greater the presence of silica in soils (represented by the kaolinite). On the other hand, lower values of RCGb show a tendency for greater amounts of alumina (gibbsite) to be present in soils. There was not an apparent variation in soil color that suggests no different weathering degrees of soils in the areas (Figure 2). But the application of RCGb index showed that the soils of São João D’Aliança (SJA) and Niquelândia (NIQ) have different weathering degrees (Figure 3). AVIRIS data processing allowed for a better division of the areas according to the weathering degree of their soils, because the result is not based only on soil color or the morphology of the terrain, but on the relation of the minerals by means of spectral analysis.

SJA area presented soils with smaller variation in weathering degree, depicted by a less intense tonal variation than the region of NIQ (Figure 3 ). The lighter portion of the terrain in SJA area (Figure 3) presents a gentle and long slope that may be a result of either new soil formation or a less eroded area. The darker portion of the soil spot in SJA (Figure 3) represents a small deep depression, which was eroded and currently accumulates more water. Higher amounts of water make soils and parent materials more subject to alterations, and less silica and more aluminum remain in these soils. In the lighter parts of NIQ (Figure 3) may occur deposition of silica as this area is at the foot hill of the Ultramafic unit. The terrain inclination results in water accumulation, silica removal, and the consequent relative concentration of aluminum in these soils. The RCGb shows such soils in darker color (Figure 3).
TABLE 1: RCGb obtained by means of TGA and AVIRIS data for samples collected in São João D'Aliança (SJA) and in Niquelândia (NIQ).

\begin{tabular}{lcccc}
\hline \multirow{2}{*}{ Soil samples } & \multicolumn{2}{c}{ Minerals $(\%)$} & \multicolumn{2}{c}{ RCGb } \\
& Gibbsite & Kaolinite & TGA & AVIRIS \\
\hline SJA 1 & 11.68 & 32.81 & 0.74 & 0.73 \\
SJA 2 & 13.84 & 34.53 & 0.71 & 0.76 \\
SJA 3 & 14.10 & 52.95 & 0.79 & 0.76 \\
SJA 4 & 11.71 & 57.99 & 0.83 & 0.76 \\
SJA 5 & 13.18 & 60.79 & 0.82 & 0.76 \\
SJA 6 & 14.16 & 60.14 & 0.81 & 0.75 \\
SJA 7 & 14.22 & 55.61 & 0.80 & 0.73 \\
SJA 8 & 16.30 & 54.75 & 0.77 & 0.72 \\
SJA 9 & 18.64 & 55.47 & 0.75 & 0.70 \\
SJA 10 & 19.02 & 53.17 & 0.74 & 0.69 \\
SJA 11 & 22.86 & 52.59 & 0.70 & 0.66 \\
SJA 12 & 23.27 & 54.53 & 0.70 & 0.64 \\
SJA 13 & 25.66 & 55.04 & 0.68 & 0.64 \\
NIQ 1 & 30.66 & 19.71 & 0.39 & 0.52 \\
NIQ 2 & 26.38 & 35.13 & 0.57 & 0.56 \\
NIQ 3 & 23.08 & 39.69 & 0.63 & 0.58 \\
NIQ 4 & 26.35 & 33.70 & 0.56 & 0.58 \\
NIQ 5 & 27.09 & 54.85 & 0.67 & 0.60 \\
NIQ 6 & 27.17 & 53.56 & 0.66 & 0.61 \\
NIQ 7 & 24.98 & 47.61 & 0.66 & 0.62 \\
NIQ 8 & 13.84 & 52.87 & 0.79 & 0.65 \\
NIQ 9 & 20.71 & 52.28 & 0.72 & 0.68 \\
NIQ 10 & 20.73 & 52.34 & 0.72 & 0.68 \\
NIQ 11 & 21.34 & 47.67 & 0.69 & 0.69 \\
NIQ 12 & 16.16 & 61.72 & 0.79 & 0.69 \\
NIQ 13 & 19.06 & 50.27 & 0.73 & 0.70 \\
NIQ 14 & 14.55 & 56.65 & 0.80 & 0.81 \\
NIQ 15 & 7.61 & 57.25 & 0.88 & 0.81 \\
NIQ 16 & 6.51 & 58.81 & 0.90 & 0.82 \\
NIQ 17 & 11.49 & 60.97 & 0.84 & 0.68 \\
\hline & & & &
\end{tabular}

AVIRIS data have been showed to be appropriate for quantifying the weathering degrees of the imaged soils. The reddish Oxisol in SJA had 11.7-25.7\% of gibbsite and $32.8-60.8 \%$ of kaolinite. NIQ soils presented $23.1-30.6 \%$ of gibbsite, $19.7-54.8 \%$ of kaolinite (dark reddish brown Oxisol, NIQ 1-NIQ 5), and 6.5-19.0\% of gibbsite, 50.2$61.7 \%$ of kaolinite (Ultisol; NIQ 12-NIQ17, Table 1). A soil transitional area occurred between the two last soils types that correspond to plots NIQ 6-NIQ 11 on Table 1 . This area showed a gradual variation in mineral amounts between the dark reddish brown Oxisol and the Ultisol (Table 1). Except for the plot named NIQ 1 (Table 1), soils in SJA and NIQ areas are kaolinitic, according to the Brazilian soil classification system [39]. NIQ 1 topographic position, where water accumulates, may explain such a difference of gibbsite and kaolinite concentrations. From the agricultural point of view, kaolinitic and gibbsitic soils demand different 


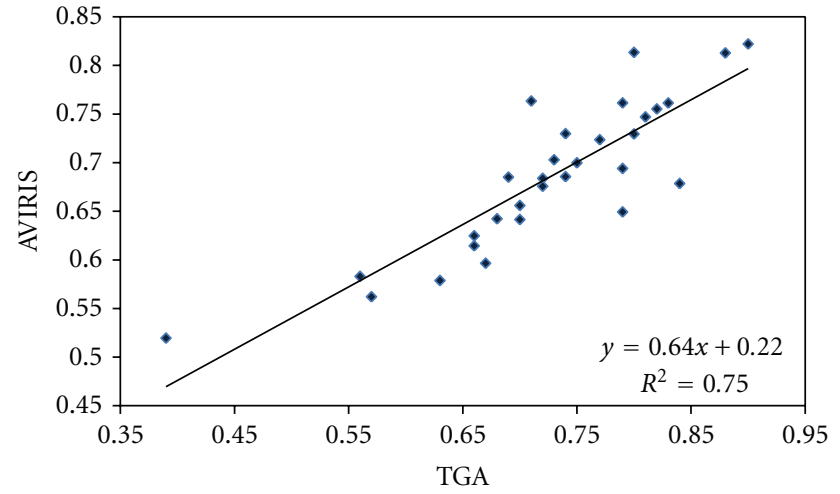

Figure 4: Regression of AVRIS data on TGA values obtained in laboratory.

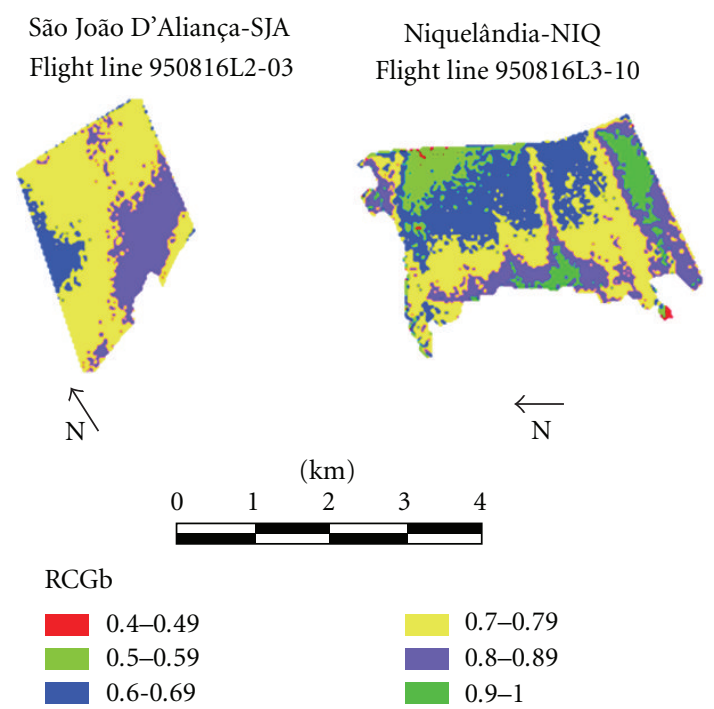

FIGURE 5: Quantitative mapping of the ratio kaolinite/(kaolinite + gibbsite).

chemical treatments. The use of RCGb identified differences in kaolinite and gibbsite contents within a same soil type as well (Figure 3 ) that can potentially optimize fertilizer applications if this characteristic is taken into account.

RCGb values were calculated from the proportions of kaolinite and gibbsite in the soils samples (TGA) presented and good fit $\left(R^{2}=0.75 ; P<.01\right)$ on RCGb calculated from AVIRIS data (Table 1; Figure 4). The Mann-Whitney or $U$ test showed no differences of RCGb values between the two AVIRIS and TGA. For SJA, $n_{1}$ and $n_{2}=13 e U_{\text {calc }}=50$ and $U_{\text {calc }}^{\prime}=118$; if $U_{\text {calc }}^{\prime} \geq U_{\text {tab }}$ or if $U_{\text {calc }}<U_{\text {tab }}$, reject $H_{0}$, if not do not reject $H_{0}$. For the greater $U_{\text {tab }}=121$ and the lesser $U_{\mathrm{tab}}=45$, for $n_{1}$ and $n_{2}=13$ and $\alpha=0.05$, therefore do not reject $\mathrm{H}_{0}$ and the two populations are the same. For NIQ, $n_{1}$ and $n_{2}=17$ and $U_{\text {calc }}=105,5$ e $U_{\text {calc }}^{\prime}=183,5$. For the greater $U_{\mathrm{tab}}=202$ and the lesser $U_{\mathrm{tab}}=87$, for $n_{1}$ and $n_{2}=17 \mathrm{e} \alpha=0,05$, do not reject $H_{0}$ and the two sample populations are also the same. Therefore, TGA and AVIRIS are independent, $H_{0}$ is true, and TGA $\approx$ AVIRIS.
Dark reddish brown Oxisol in NIQ has a significant amount of opaque minerals such as magnetite $\left(\mathrm{Fe}_{3} \mathrm{O}_{4}\right)$, which may reduce the efficiency of the spectral index. However, there was a good relationship between AVIRIS data and TGA values and this made it possible to spread out the quantitative mapping through the terrain (Figure 5). SJA presented three weathering degrees of kaolinitic soils, and NIQ had two plots of gibbsitic soils and five variations in the weathering degree of kaolinitic soils at 1:50,000 scale.

\section{Conclusions}

Conjoint treatment of images of bare soils from two different geological contexts showed that the AVIRIS sensor is able of capturing features to demonstrate that soils with different amounts of kaolinite and gibbsite can be investigated by means of the RCGb spectral index.

RCGB index could capture differences in amounts of kaolinite and gibbsite for a same soil type over a continuous area and depict its weathering degree.

The method can be utilized on a large scale due to the fact that this remote hyperspectral sensor is available on an orbital platform, favoring multitemporal analyses.

Further research should be carried out to better comprehend the factors that influence spectral features and to discover new mineral ratios, to improve spectroscopy as a method for mineralogical identification and quantification of tropical soils.

\section{Acknowledgments}

The authors would like to thank $\mathrm{CNPq}$ and Embrapa for funding this paper, and they also extend their thanks to NASA's Jet Propulsion Laboratory, in the person of Robert O. Green who furnished the AVIRIS data, which were fundamental to carrying out this study. Finally, the authors thank Professor Cynthia Ann Bell-Santos, of NMSU, for review and translation to English.

\section{References}

[1] E. Ben-Dor, S. Chabrillat, J. A. M. Demattê et al., "Using Imaging Spectroscopy to study soil properties," Remote Sensing of Environment, vol. 113, no. 1, pp. S38-S55, 2009.

[2] J. S. Madeira Netto, Étude Quantitative des Relations Constituants Minéralogiques-Réflectance Diffuse des Latosols Brésiliens, Application à l'Utilisation Pédologique des Données Satellitaires TM (Région de Brasilia), l'ORSTOM, Paris, France, 1993.

[3] S. A. Bowers and R. J. Hanks, "Reflectance of radiant energy from soils," Soil Science, vol. 100, pp. 130-138, 1965.

[4] D. S. Orlov, "Quantitative patterns of light reflection by soils. I. Influence of particles (aggregate) size on reflectivity," Science Papers of High School Biology, vol. 4, pp. 206-210, 1966.

[5] I. I. Karmanov, "Genesis and geography of soils: application of spectrophotometric coefficients to the study of soil-forming processes," Soviet Soil Science, vol. 2, pp. 152-165, 1968. 
[6] W. Flaig, H. Beutelspacher, and E. Rietz, "Chemical composition and physical properties of humic substances," in Soil Components, J. E. Gieseking, Ed., vol. 1 of Organic Components, Springer, New York, NY, USA, 1975.

[7] J. Hlavay, K. Jonas, S. Elek, and J. Inczedy, "Characterization of the particle size and the crystallinity of certain minerals by infrared spectrophotometry and other instrumental methodsI. Investigations on clay minerals," Clays and Clay Minerals, vol. 25, no. 6, pp. 451-456, 1977.

[8] A. Bedidi, B. Cervelle, J. Madeira, and M. Pouget, "Moisture effects on visible spectral characteristics of lateritic soils," Soil Science, vol. 153, no. 2, pp. 129-141, 1992.

[9] J. Madeira Netto, "Spectral reflectance properties of soils," Photo Interpretation: Images Aeriennes et Spatiales, vol. 34, no. 2, pp. 59-76, 1996.

[10] J. Madeira, A. Bedidi, M. Pouget, B. Cervelle, and N. Flay, "Spectral (MIR) determination of kaolinite and gibbsite contents in lateritic soils," Comptes Rendus-Academie des Sciences, vol. 321, no. 2, pp. 119-128, 1995.

[11] J. Madeira, A. Bédidi, B. Cervelle, M. Pouget, and N. Flay, "Visible spectrometric indices of hematite $(\mathrm{Hm})$ and goethite (Gt) content in lateritic soils: the application of a Thematic Mapper (TM) image for soil-mapping in Brasilia, Brazil," International Journal of Remote Sensing, vol. 18, no. 13, pp. 2835-2852, 1997.

[12] M. M. Valeriano, J. C. N. Epiphanio, A. R. Formaggio, and J. B. Oliveira, "Bi-directional reflectance factor of 14 soil classes from Brazil," International Journal of Remote Sensing, vol. 16, no. 1, pp. 113-128, 1995.

[13] L. S. Galvão and I. Vitorello, "Role of organic matter in obliterating the effects of iron on spectral reflectance and colour of Brazilian tropical soils," International Journal of Remote Sensing, vol. 19, no. 10, pp. 1969-1979, 1998.

[14] J. A. M. Demattê and G. J. Garcia, "Alteration of soil properties through a weathering sequence as evaluated by spectral reflectance," Soil Science Society of America Journal, vol. 63, no. 2, pp. 327-342, 1999.

[15] J. A. M. Demattê, R. C. Campos, and M. C. Alves, "Avaliação espectral de solos desenvolvidos em uma toposseqüência de diabásio e folhelho da região de Piracicaba, SP.," Pesquisa Agropecuaria Brasileira, vol. 35, no. 12, pp. 2447-2460, 2000.

[16] J. A. M. Demattê, A. R. Huete, L. G. Ferreira Jr., M. C. Alves, M. Nanni, and C. E. Cerri, "Evaluation of tropical soils through ground and orbital sensors," in Proceedings of the 2nd International Conference on Geospatial Information in Agriculture and Forestry, 2000.

[17] D. J. Brown, K. D. Shepherd, M. G. Walsh, M. Dewayne Mays, and T. G. Reinsch, "Global soil characterization with VNIR diffuse reflectance spectroscopy," Geoderma, vol. 132, no. 3-4, pp. 273-290, 2006.

[18] D. Summers, M. Lewis, B. Ostendorf, and D. Chittleborough, "Visible near-infrared reflectance spectroscopy as a predictive indicator of soil properties," Ecological Indicators, vol. 11, pp. 123-131, 2001.

[19] V. Carrere and M. J. Abrams, "An assessment of AVIRIS data for hydrothermal alteration mapping in the Goldfield mining district, Nevada," in Proceedings of the Airborne Visible/Infrared Imaging Spectro, pp. 134-154, JPL Publication, Pasadena, Calif, USA, 1988.

[20] G. M. M. Baptista, E. S. Martins, J. S. Madeira Netto, O. A. Carvalho Jr., and P. R. Meneses, "Use of AVIRIS data for mineralogical mapping in tropical soils, in the district of São
João D'Alianca," in Proceedings of the AVIRIS Earth Science and Applications Workshop, pp. 33-42, JPL Publications, Goiás, Brazil, 1998.

[21] G. M. M. Baptista, J. S. Madeira Netto, O. A. Carvalho Jr., and P. R. Meneses, "Mapping kaolinite and gibbsite of Brazilian tropical soils using imaging spectrometry data (AVIRIS)," in Proceedings of the AVIRIS Earth Science and Applications Workshop, pp. 267-274, JPL Publications, 1999.

[22] V. Carrere and O. Chadwick, "An AVIRIS survey of Quaternary surfaces formed on carbonate provenance alluvium, Mojave Desert, southern Nevada," in Proceedings of the 2nd Airborne Visible/Infrared Imaging Spectrometer (AVIRIS) Workshop, 1990.

[23] R. N. Clark, A. Gallagher, and G. A. Swayze, "Material absorption band depth mapping of imaging spectrometer data using a complete band shape least-squares fit with library reference spectra," in Proceedings of the 2nd Airborne Visible/Infrared Imaging Spectrometer (AVIRIS) Workshop, pp. 176-186, JPL Publications, 1990.

[24] R. N. Clark, G. A. Swayze, A. Gallagher, N. Gorelick, and F. A. Kruse, "Mapping with imaging spectrometer data using the complete band shape least-squares algorithm simultaneously fit to multiple spectral features from multiple materials," in Proceedings of the 3rd Airborne Visible/Infrared Imaging Spectrometer (AVIRIS) Workshop, pp. 2-3, JPL Publication, 1991.

[25] R. N. Clark, G. A. Swayze, and A. Gallagher, "Mapping the mineralogy and lithology of Canyonlands, Utah with imaging spectrometer data and the multiple spectral feature mapping algorithm," in Proceedings of the 3rd Annual JPL Airborne Geoscience Workshop, pp. 11-13, JPL Publication, 1992.

[26] R. N. Clark, "Spectroscopy of rocks and minerals, and principles of spectroscopy," in Manual of Remote Sensing, A. N. Rencz, Ed., vol. 3 of Remote Sensing for the Earth Science, John Wiley \& Sons, New York, NY, USA, 1999.

[27] G. M. M. Baptista and J. S. Madeira Netto, "RCGb Index: a tool for mapping the weathering degree of the tropical soils in Brazil," in Proceedings of the AVIRIS Earth Science and Applications Workshop, Jet Propulsion Laboratory (JPL) NASA, Pasadena, Calif, USA, 2001.

[28] A. P. Crósta, C. Sabine, and J. V. Taranik, "A comparison of image processing methods for alteration mapping at Bodie, California, using 1992 AVIRIS data," in Proceedings of the 6th Annual JPL Airborne Earth Sciences Workshop, vol. 1, pp. 5762, JPL Publication, 1996.

[29] E. Ben-Dor, N. Levina, A. Singer, A. Karnieli, O. Braund, and G. J. Kidrona, "Quantitative mapping of the soil rubification process on sand dunes using an airborne hyperspectral sensor," Geoderma, vol. 131, pp. 1-21, 2006.

[30] E. Ben-Dor, R. G. Taylor, J. Hill et al., "Imaging spectrometry for soil applications," Advances in Agronomy, vol. 97, pp. 321392, 2001.

[31] L. S. Galvão, A. R. Formaggio, E. G. Couto, and D. A. Roberts, "Relationships between the mineralogical and chemical composition of tropical soils and topography from hyperspectral remote sensing data," ISPRS Journal of Photogrammetry and Remote Sensing, vol. 63, no. 2, pp. 259-271, 2008.

[32] G. Serbin, C. S. T. Daughtry, E. R. Hunt, J. B. Reeves, and D. J. Brown, "Effects of soil composition and mineralogy on remote sensing of crop residue cover," Remote Sensing of Environment, vol. 113, no. 1, pp. 224-238, 2009.

[33] G. M. M. Baptista, Mapeamento e Quantificação da Relação Mineralógica Caulinita/(Caulinita+Gibbsita) de Solos Tropicais, por meio dos Dados do Sensor Hiperespectral AVIRIS 
(JPL/NASA), Tese (Doutorado), Universidade de Brasília, Brasília, Brazil, 2001.

[34] P. Lagacherie, F. Baret, J. B. Feret, J. Madeira Netto, and J. M. Robbez-Masson, "Estimation of soil clay and calcium carbonate using laboratory, field and airborne hyperspectral measurements," Remote Sensing of Environment, vol. 112, no. 3, pp. 825-835, 2008.

[35] R. O. Green, J. E. Conel, J. S. Margolis, C. J. Brugge, and G. L. Hoover, "An inversion algorithm for retrieval of atmospheric and leaf water absorption from AVIRIS radiance with compensation for atmospheric scattering," in Proceedings of the 3rd Airborne Visible/Infrared Imaging Spectrometer (AVIRIS) Workshop, pp. 51-61, JPL Publications, 1991.

[36] BO. C. Gao, K. B. Heidebrecht, and A. F. H. Goetz, "Derivation of scaled surface reflectances from AVIRIS data," Remote Sensing of Environment, vol. 44, no. 2-3, pp. 165-178, 1993.

[37] B. C. Gao, K. B. Heidebrecht, and A. F. H. Goetz, "Atmosphere REMoval Program (ATREM) user's guide," Version 3.1. CSES/CIRES/University of Colorado. Boulder, Colo, USA, 1999.

[38] J. H. Zar, Biostatistical Analysis, Prentice Hall, New York, NY, USA, 1989.

[39] Embrapa, Sistema Brasileiro de Classificação de Solos, Serviço de Produção de Informação, Brasília, Brazil, 1st edition, 1999. 

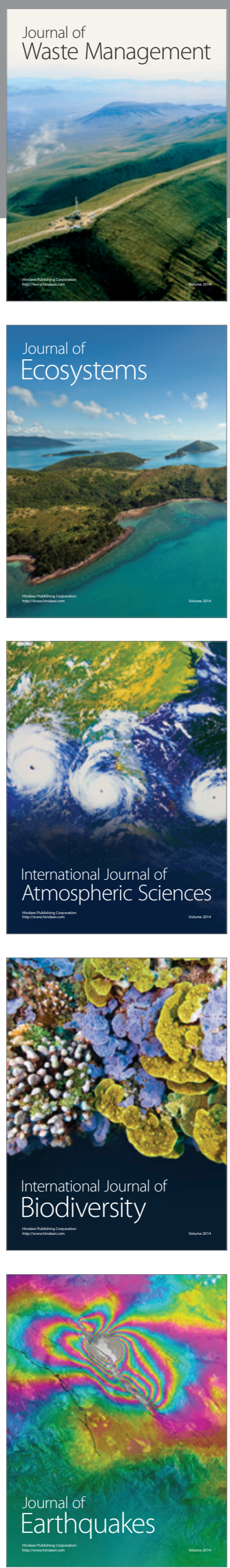
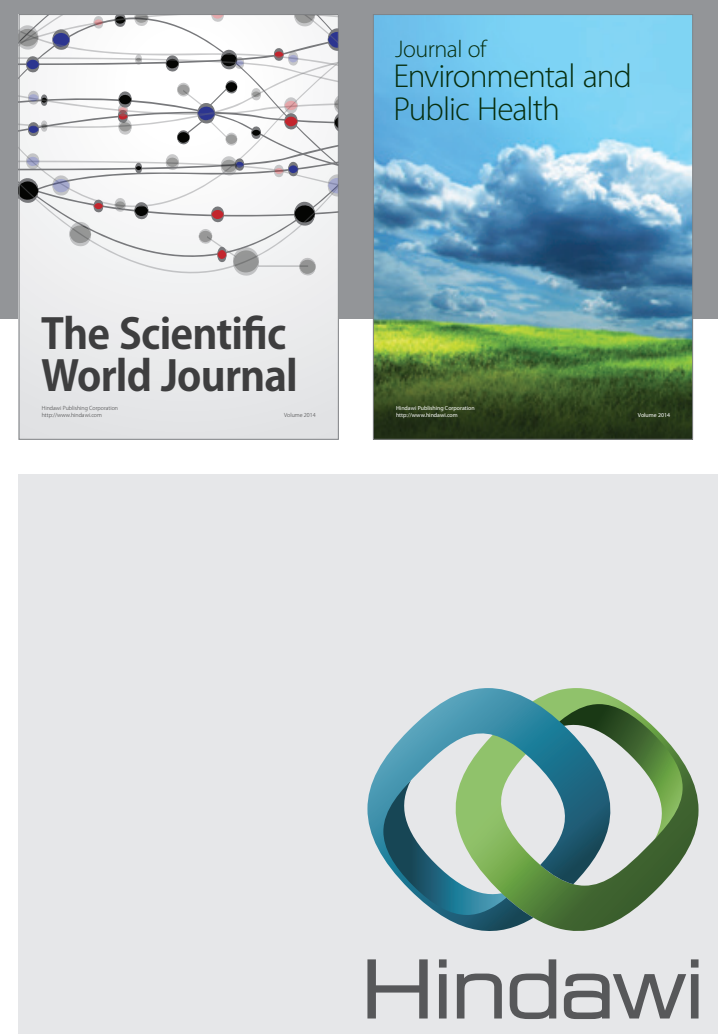

Submit your manuscripts at

http://www.hindawi.com
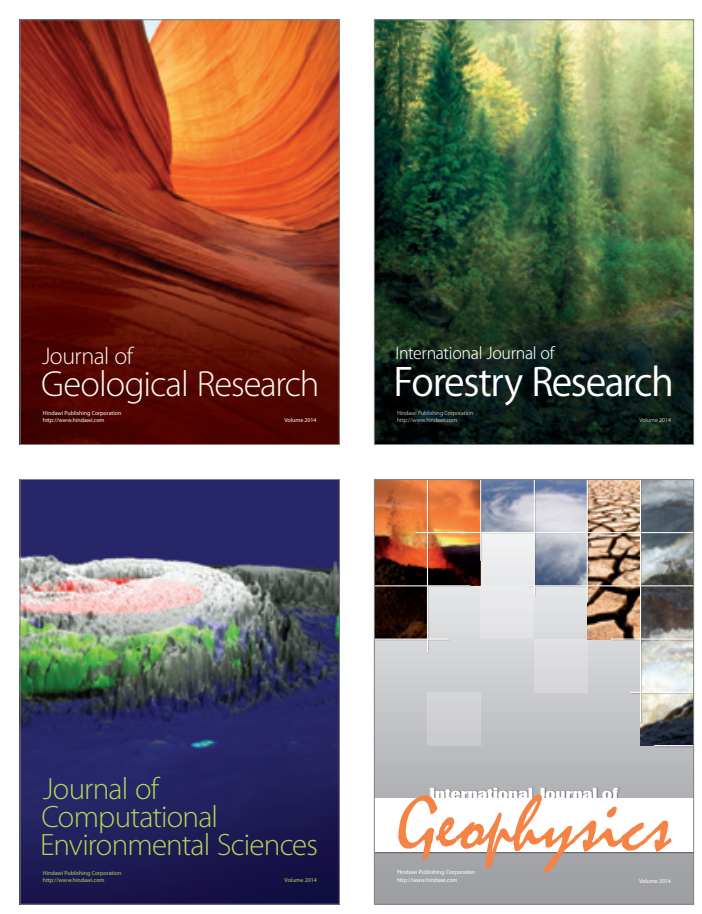
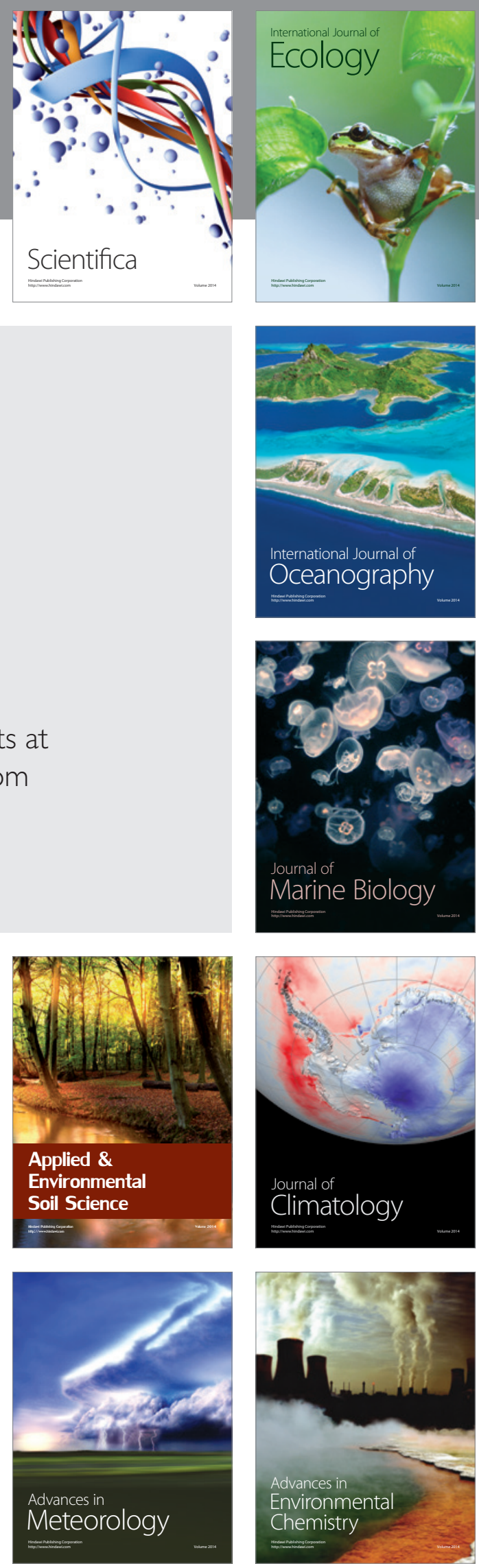